\title{
Mechanical Properties of Epoxy Composite Materials Produced with Different Ceramic Powders
}

\author{
Yelda Akçin Ergün \\ Department of Metallurgical and Material Engineering, Faculty of Technology, Afyon Kocatepe University, \\ Afyonkarahisar, Turkey \\ Email: yeldaakcin@aku.edu.tr
}

How to cite this paper: Ergün, Y.A. (2019) Mechanical Properties of Epoxy Composite Materials Produced with Different Ceramic Powders. Journal of Materials Science and Chemical Engineering, 7, 1-8. https://doi.org/10.4236/msce.2019.712001

Received: November 2, 2019

Accepted: December 7, 2019

Published: December 10, 2019

Copyright $\odot 2019$ by author(s) and Scientific Research Publishing Inc. This work is licensed under the Creative Commons Attribution International License (CC BY 4.0).

http://creativecommons.org/licenses/by/4.0/

\section{c) (i) Open Access}

\begin{abstract}
In this study, production and mechanical properties of polymer composite materials obtained by using $\mathrm{Al}_{2} \mathrm{O}_{3}, \mathrm{SiO}_{2}, \mathrm{MgO}$ and $\mathrm{TiO}_{2}$ hard ceramic fillers were studied. Epoxy resin was used as the matrix material, and four different ceramic powders were mechanically mixed into the resin at $3 \%$ and $5 \%$ as reinforcement. The mechanical properties of the polymer composite materials were then characterized. For this purpose, flexural modulus and flexural strength of composite materials were determined by using three point bending test and impact toughness of the materials were determined by Charpy impact test. In addition, the hardness values of the samples were determined by Shore D hardness test.
\end{abstract}

\section{Keywords}

Polymer Composite, Epoxy, Ceramic Powders, Mechanical Properties

\section{Introduction}

Materials science is a science based on the development of new materials or the improvement of the performance of existing materials. Epoxy resins, which have superior properties such as high strength and corrosion resistance, chemical stability, easy processing, and low shrinkage during hardening, have been a favorite of materials engineers trying to develop new composite materials. In addition, due to their good wetting properties, composite material can be formed by combining with many materials [1]. Due to these characteristics of epoxy composite materials are candidates to take the place of conventional metallic materials. But the cross-links found in the structure of the epoxy resin, which gives it strength, 
make it a brittle material at the same time. Brittle material means material that allows crack propagation and is damaged by sudden breakage. In addition, although the strength of epoxies is high, it is not sufficient compared to metals. It has been shown in many studies that the addition of inorganic particulate fillers to the resin can increase the modulus, strength and many more properties of the epoxy resin. Most commonly used types of inorganic reinforcing particles are $\mathrm{Al}_{2} \mathrm{O}_{3}, \mathrm{SiO}_{2}$ and $\mathrm{TiO}_{2}$. Researchers in the literature investigated the effect of $\mathrm{Al}_{2} \mathrm{O}_{3}$ additive on the mechanical and some other properties of polymer composites and all of them concluded that the mechanical properties improved [2] [3] [4] [5]. Zhao and Wenbo Luo investigated the effect of nano silica fillers on the mechanical properties of the epoxy composite. They concluded that the elastic modules of the nano $\mathrm{SiO}_{2}$ /epoxy composite were greater than those of pure epoxy resins. However, the \% elongation of the composite material decreased with increasing $\mathrm{SiO}_{2}$ content by weight [6]. Chen and friends investigated the effect of highly dispersed nano silica admixture in epoxy resin in their studies. There was a significant increase in the mechanical properties of the nano $\mathrm{SiO}_{2}$ filled composite [7]. Johnsen and friends noted that as a result of their studies, the addition of silica nanoparticles to epoxy increased toughness and modulus [8]. Ahmad and friends investigated the effect of $\mathrm{SiO}_{2}$ particle shape on epoxy composites and concluded that elongated silica provides the best mechanical properties compared to other shapes [9]. In the literature, there are many studies showing that $\mathrm{TiO}_{2}$ additive provides an increase in the mechanical properties of epoxy [10] [11] [12] [13].

In this study, epoxy composite materials with $\mathrm{Al}_{2} \mathrm{O}_{3}, \mathrm{SiO}_{2}$, and $\mathrm{TiO}_{2}$ which are frequently used in the literature, and with $\mathrm{MgO}$, which is not used much, were produced to investigate which reinforcement material caused better mechanical properties.

\section{Experimental Studies}

\subsection{Production of Samples}

This study was carried out in Afyon Kocatepe University Faculty of Technology Laboratories. MGS LR160 HEXION epoxy resin and hardener were used to determine the characteristics and mechanical properties of epoxy matrix, $\mathrm{Al}_{2} \mathrm{O}_{3}$, $\mathrm{SiO}_{2}, \mathrm{MgO}$ and $\mathrm{TiO}_{2}$ reinforced composite materials. The reinforcing materials and their properties are given in Table 1.

In order to determine the mechanical properties of composite materials, composite materials having filler rates of $3 \%$ and $5 \%$ by weight were produced.

Table 1. The reinforcing materials and their properties.

\begin{tabular}{ccccc}
\hline Reinforcement & $\mathrm{Al}_{2} \mathrm{O}_{3}$ & $\mathrm{SiO}_{2}$ & $\mathrm{TiO}_{2}$ & $\mathrm{MgO}$ \\
\hline Purity $(\%)$ & 97.7 & 99 & 98 & 98 \\
Density $\left(\mathrm{gr} / \mathrm{cm}^{3}\right)$ & 3.95 & 2.32 & 4.25 & 3.58 \\
Average Particle Size $(\mu \mathrm{m})$ & 2 & 2 & 0.2 & 2 \\
\hline
\end{tabular}


For the production of samples, epoxy and hardener were used according to the mixing ratio of 100:25. In all productions, firstly, a homogeneous mixture was obtained by adding ceramic filler material to the epoxy and mixing with mechanical mixer for 20 minutes. Then, the hardener was added and stirring was continued for a further 5 minutes, thus preventing the epoxy from starting to cure during the mixing of the reinforcing material. After the mechanical stirring process, the mixture which was taken to the vacuum apparatus to remove air bubbles was vacuumed at variable pressures for 15 minutes. The mixture was then poured into silicone molds and allowed to cure at room temperature for 24 hours (Figure 1). Following the production process, three points bending, impact and hardness tests were performed on the samples, respectively, and the results were compared.

\subsection{Mechanical Tests}

\subsubsection{Bending Test}

SHIMADZU 3 point bending test instrument was used to determine the bending behavior of the samples. The distance between the brackets was $58 \mathrm{~mm}$ and the jaw speed was $2 \mathrm{~mm} / \mathrm{min}$. The maximum stress and elastic modulus of pure epoxy, $3 \%$ and $5 \%$ reinforced composite materials were obtained by bending test and the results are given in Figure 2 and Figure 3. When the maximum bending graph given in Figure 2 is examined, it is seen that all additive increases the flexural strength of epoxy. In addition, as the amount of additive material increased, strength increased. The highest increase was observed in 5\% and 3\% $\mathrm{SiO}_{2}$ added samples, respectively. $\mathrm{TiO}_{2}$ additives followed them. The critical point that affects the mechanical properties when preparing particle reinforced composite materials is the good dispersion of the particles in the resin [11] [14]. Although there are many parameters affecting the distribution, the density and size of the particles are among the most important factors. $\mathrm{SiO}_{2}$, which has the lowest density of the reinforcing materials, also showed a good distribution during production. This was reflected in the results. The highest strength value is obtained from $5 \% \mathrm{SiO}_{2}$ composite material. This was followed by $3 \% \mathrm{SiO}_{2}$ doped sample, $5 \% \mathrm{TiO}_{2}$ and $3 \% \mathrm{TiO}_{2}$ doped samples, respectively. Although $\mathrm{TiO}_{2}$ is the additive having the highest density, it has a good distribution since it has the
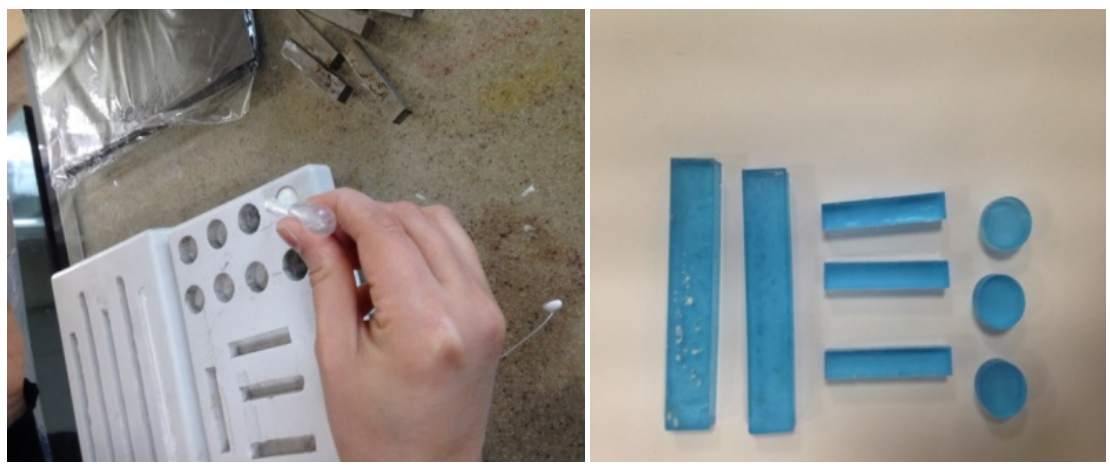

Figure 1. Silicone molds for sample production and produced samples. 


\section{Flexural Strength (MPa)}



Figure 2. Flexural strength of samples.



Figure 3. Flexural stiffness of samples.

smallest grain size and this is seen from the strength results. The highest strength value is obtained from $5 \% \mathrm{SiO}_{2}$ doped composite material. This was followed by $3 \% \mathrm{SiO}_{2}$ doped sample, $5 \% \mathrm{TiO}_{2}$ and $3 \% \mathrm{TiO}_{2}$ doped samples. Although $\mathrm{TiO}_{2}$ is the additive having the highest density, it has a good distribution since it has the smallest grain size and this is seen from the strength results. Some precipitation was observed when the $\mathrm{Al}_{2} \mathrm{O}_{3}$ powders were mixed into the epoxy resin and allowed to cure. In the case of the samples produced with $\mathrm{MgO}$ powders, on the contrary, the accumulation of the powders on the surface was observed. Although they do not show a good distribution, the introduction of hard particles into the system increased the strength, but not as much as the well dispersed $\mathrm{SiO}_{2}$ and $\mathrm{TiO}_{2}$ supplements. This increase shows that bonding between the reinforcing particles and the matrix material has been formed to transmit the external charge [15] [16].

Flexural modules of the samples are given in Figure 3. When the graph is examined, it is seen that the additives nearly double the flexural modulus compared to pure epoxy. There was no significant difference between the modules obtained as a result of $3 \%$ and $5 \%$ additions by weight. The highest result is seen in the sample with $5 \% \mathrm{MgO}$ added, but all results are close to each other. Increased interface with reinforcing particles increased bending modules [5]. 


\subsubsection{Impact Test}

Impact toughness of the composites was determined by Charpy Impact Device. The Charpy impact test is one of the most effective impact tests that assess the behavior of a material subjected to dynamic loads. For the Charpy impact test, samples were prepared unnotched because epoxy is already a brittle material. Figure 4 gives the results of toughness obtained. When the graph is examined, it is seen that $5 \% \mathrm{TiO}_{2}$ doped sample gives the best impact toughness result. The test results show that the smallest $\mathrm{TiO}_{2}$ particles exhibit a good dispersion and increase impact toughness. When $\mathrm{SiO}_{2}$ doped samples were compared with $\mathrm{TiO}_{2}$ doped samples, it was seen that grain size was a more important factor for impact toughness. $\mathrm{TiO}_{2}$ reinforcement with high density but lower grain size gave better results in impact test.

Bending strength and bending stiffness were still increased in $\mathrm{Al}_{2} \mathrm{O}_{3}$ and $\mathrm{MgO}$-reinforced samples that could not be produced homogeneously. However, the impact toughness results are reduced when compared to pure epoxy. If homogeneous mixing is not effective in particle-reinforced composite materials, the particle agglomerates remaining as stress concentrators in the matrix may act as notches. If the particles act as strong stress points, the impact energy of the epoxy matrix is expected to decrease as more particles are added [7]. This was observed in $\mathrm{Al}_{2} \mathrm{O}_{3}$ and $\mathrm{MgO}$ added samples. Precipitated $\mathrm{Al}_{2} \mathrm{O}_{3}$ and floating $\mathrm{MgO}$ particles decreased the impact toughness of epoxy.

\subsubsection{Hardness Test}

Hardness is considered one of the most important factors affecting the abrasion resistance of any material. In this study, the hardness (Shore D) values of epoxy composites reinforced with $3 \%$ and $5 \%$ hard ceramic particles were obtained and compared with pure epoxy. An average value was determined by taking 10 measurements from each sample. The obtained hardness values are given in Figure 5. The results show that the incorporation of rigid reinforcing elements into the epoxy resulted in a significant improvement in the hardness of the composites. The mechanical properties of particle reinforced composites generally depend

\section{Impact Strength $\left(\mathrm{J} / \mathrm{cm}^{2}\right)$}

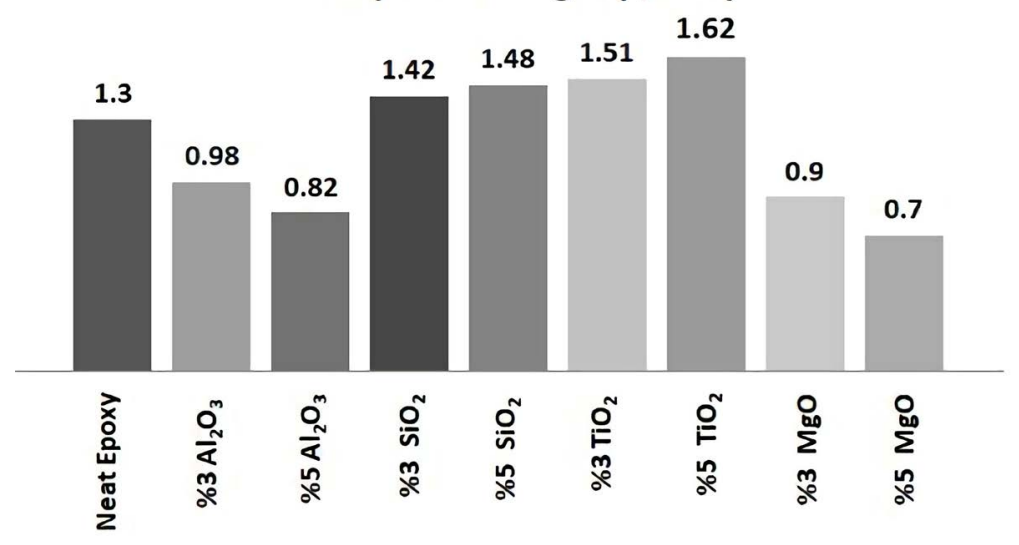

Figure 4. Impact strength of samples. 


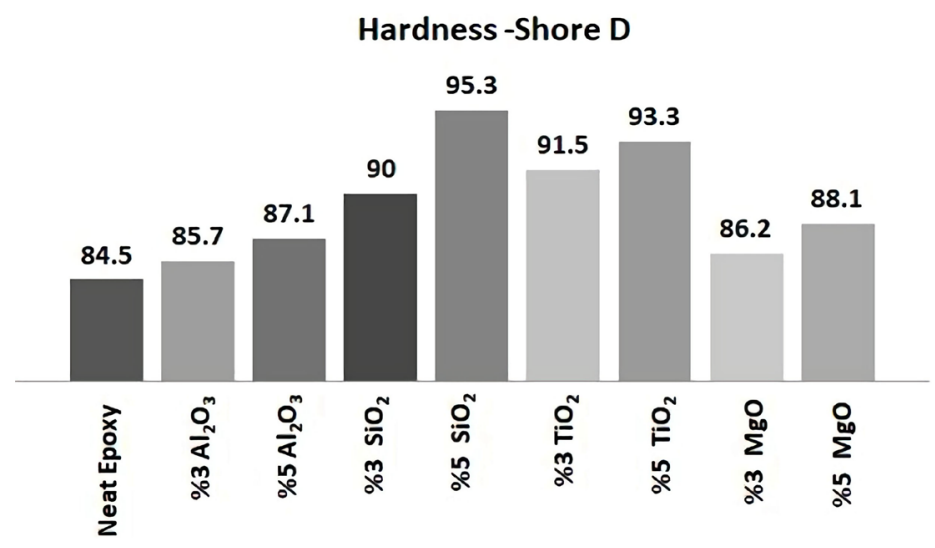

Figure 5. Hardness of Shore D results.

on factors such as reinforcing content, particle size and shape, the degree of bond between the filler and the polymer matrix, and the distribution of the filler in the matrix. The improvement in hardness is due to the presence of hard particles on the surface of the epoxy matrix and a sufficient dispersion. While the well distributed $\mathrm{SiO}_{2}$ and $\mathrm{TiO}_{2}$ additives increased the hardness value along the surface, the poorly distributed $\mathrm{Al}_{2} \mathrm{O}_{3}$ and $\mathrm{MgO}$ additives caused the surface hardness to be variable and as a result the average hardness was low.

\section{Results}

- In this study, $\mathrm{Al}_{2} \mathrm{O}_{3}, \mathrm{SiO}_{2}, \mathrm{TiO}_{2}$, and $\mathrm{MgO}$ doped epoxy composite materials produced and investigated mechanical properties of them to determine which reinforcement material caused better mechanical properties.

- As a result of bending test, all reinforcement materials increased flexural stiffness and modulus. Flexural strength increased as the amount of additive increased but there was no significant change in the modules with the increase in the amount of additive.

- The best results in flexural strength and modulus are obtained from $5 \% \mathrm{SiO}_{2}$ additive. This was followed by $3 \% \mathrm{SiO}_{2}$ doped sample, $5 \% \mathrm{TiO}_{2}$ and $3 \% \mathrm{TiO}_{2}$ doped samples, respectively. Although $\mathrm{TiO}_{2}$ is the additive having the highest density, it has a good distribution since it has the smallest grain size and this is seen from the strength results.

- According to impact test $\mathrm{TiO}_{2}$ particles increased the impact toughness. Small and well dispersed grains are prevented crack formation.

- The hardness results show that the incorporation of rigid reinforcing elements into the epoxy resulted in a significant improvement in the hardness of the composites. While the well distributed $\mathrm{SiO}_{2}$ and $\mathrm{TiO}_{2}$ additives increased the surface hardness, the poorly distributed $\mathrm{Al}_{2} \mathrm{O}_{3}$ and $\mathrm{MgO}$ additives reduced.

\section{Conclusions}

$\mathrm{Al}_{2} \mathrm{O}_{3}, \mathrm{SiO}_{2}, \mathrm{TiO}_{2}, \mathrm{MgO}$ additives improved the flexural strength and flexural 
modulus of epoxy composite material. However, one of the most important factors affecting the mechanical properties of particle reinforced composite materials is distribution [11] [14]. The good dispersion of low density $\mathrm{SiO}_{2}$ in the resin increased the flexural strength and modulus. The same effect was also seen in hardness results. When we look at the impact results, we see that grain size has gained importance with good distribution. The $\mathrm{TiO}_{2}$ additive, which has a small grain size and is well dispersed, increased the impact strength, while the additives that are not well dispersed and which are large grain size decreased the impact strength.

This study showed that while additives that are well distributed for flexural strength, modulus and hardness give better results, when it comes to impact toughness, the grain size of the additive has also gained importance.

\section{Conflicts of Interest}

The author declares no conflicts of interest regarding the publication of this paper.

\section{References}

[1] Petrie, E. (2005) Epoxy Adhesive Formulations. McGraw Hill, New York.

[2] McGratha, M., Parnas, R.S., King, S.H., Schroeder, J.L., Fischer, D.A. and Lenhart, J.L. (2008) Investigation of the Thermal, Mechanical, and Fracture Properties of Alumina-Epoxy Composites. Polymer, 49, 999-1014. https://doi.org/10.1016/j.polymer.2007.12.014

[3] Kardara, P., Ebrahimi, M. and Bastani, S. (2008) Study the Effect of Nano-Alumina Particles on Physical-Mechanical Properties of UV Cured Epoxy Acrylate via Nano-Indentation. Progress in Organic Coatings, 62, 321-325. https://doi.org/10.1016/j.porgcoat.2008.01.015

[4] Zhao, H.X. and Li, R.K.Y. (2008) Effect of Water Absorption on the Mechanical and Dielectric Properties of Nano-Alumina Filled Epoxy Nanocomposites. Composites Part A: Applied Science and Manufacturing, 39, 602-611. https://doi.org/10.1016/j.compositesa.2007.07.006

[5] Su, Z., Schadler, L.S., Duncan, R., Hillborg, H. and Auletta, T. (2008) Mechanisms Leading to Improved Mechanical Performance in Nanoscale Alumina Filled Epoxy. Composites Science and Technology, 68, 2965-2975. https://doi.org/10.1016/j.compscitech.2008.01.009

[6] Zhao, R. and Luo, W.B. (2008) Fracture Surface Analysis on Nano-SiO $2 /$ Epoxy Composite. Materials Science and Engineering: A, 483, 313-315. https://doi.org/10.1016/j.msea.2006.08.151

[7] Chen, C., Justice, R.S., Schaefer, D.W. and Baur, J.W. (2008) Highly Dispersed Nanosilica-Epoxy Resins with Enhanced Mechanical Properties. Polymer, 49, 3805-3815. https://doi.org/10.1016/j.polymer.2008.06.023

[8] Johnsen, B.B., Kinloch, A.J., Mohammed, R.D., Taylor, A.C. and Sprenger, S. (2007) Toughening Mechanisms of Nanoparticle-Modified Epoxy Polymers. Polymer, 48, 530-541. https://doi.org/10.1016/j.polymer.2006.11.038

[9] Ahmad, F.N., Jaafar, M., Palaniandy, S. and Azizli, K.A.M. (2008) Effect of Particle Shape of Silica Mineral on the Properties of Epoxy Composites. Composites Science 
and Technology, 68, 346-353. https://doi.org/10.1016/j.compscitech.2007.07.015

[10] Chatterjee, A. and Islam, M.S. (2008) Fabrication and Characterization of $\mathrm{TiO}_{2}$-Epoxy Nanocomposite. Materials Science and Engineering: A, 487, 574-584.

https://doi.org/10.1016/j.msea.2007.11.052

[11] Hamming, L.M., Qiao, R., Messersmith, P.B. and Brinson, L.C. (2009) Effects of Dispersion and Interfacial Modification on the Macroscale Properties of $\mathrm{TiO}_{2} \mathrm{Po}-$ lymer Matrix Nanocomposites. Composites Science and Technology, 69, 1880-1886. https://doi.org/10.1016/j.compscitech.2009.04.005

[12] Mirmohseni, A. and Zavareh, S. (2010) Preparation and Characterization of an Epoxy Nanocomposite Toughened by a Combination of Thermoplastic, Layered and Particulate Nano-Fillers. Materials \& Design, 31, 2699-2706. https://doi.org/10.1016/j.matdes.2010.01.035

[13] Zhou, Y., White, E., Hosur, M. and Jeelani, S. (2010) Effect of Particle Size and Weight Fraction on the Flexural Strength and Failure Mode of $\mathrm{TiO}_{2}$ Particles Reinforced Epoxy. Materials Letters, 64, 806-809. https://doi.org/10.1016/j.matlet.2010.01.016

[14] Krishnamoorti, R. (2007) Strategies for Dispersing Nanoparticles in Polymers. Polymer Nanocomposites, 32, 341-347. https://doi.org/10.1557/mrs2007.233

[15] Zhang, M., Zeng, H., Zhang, L., Lin, G. and Li, R.K.Y. (1993) Fracture Characteristics of Discontinuous Carbon Fibre-Reinforced PPS and PES-C Composites. Polymers and Polymer Composites, 1, 357-365.

[16] Bazrgari, D., Moztarzadeh, F., Sabbagh-Alvani, A.A., Rasoulianboroujeni, M., Tahriri, M. and Tayebi, L. (2018) Mechanical Properties and Tribological Performance of Epoxy/ $\mathrm{Al}_{2} \mathrm{O}_{3}$ Nanocomposite. Ceramics International, 44, 1220-1224. https://doi.org/10.1016/j.ceramint.2017.10.068 